Original Research Paper

\title{
Dynamic Reliability Analysis of Steel Moment Frames Using Monte Carlo Technique
}

\author{
Majid Mahjoor Lotf Aabadi \\ Sama Technical and Vocational Training College, \\ Islamic Azad University, Mashhad Branch, Mashhad, Iran
}

\author{
Article history \\ Received: 7-02-2019 \\ Revised: 16-03-2019 \\ Accepted: 15-06-2019 \\ Corresponding Author: \\ Majid Mahjoor Lotf Abadi \\ Sama Technical and Vocational \\ Training College, Islamic Azad \\ University, Mashhad Branch, \\ Mashhad, Iran \\ Email: m.mahjoor-ce@aryan.ac.ir \\ majidmahjoorlotfabadi@yahoo.com
}

\begin{abstract}
Designing of structures is the function of operation of them. However, operation of the structures depends on different uncertainties. In practical cases, uncertain parameters are simplified and formulated to certain parameters which are implemented in the designing approach. In this investigation, different structural parameters which bear with uncertainties including loading conditions, strength of materials and geometry of the structural elements are modeled and simulated based on Monte Carlo technique. Nonlinear dynamic time history analyses are conducted for different structures with steel moment frames based on finite element method using OpenSees code. Different responses are monitored for different accelerograms for both far and near field faults. Based on the results, the reliability index of steel frames in far field cases are larger than in near field cases.
\end{abstract}

Keywords: Dynamic Reliability Analysis, Monte Carlo Simulation, Steel Moment Resisting Frame SMRF

\section{Introduction}

Safety analysis of structures in seismic conditions is one of the significant phases of structural design especially in urban areas with high hazard of earthquake. A review of case histories shows that in some cases even in buildings with conventional seismic design, severe earthquake failures were monitored which coincide with severe economic losses and casualties. It is noteworthy that conventional seismic design procedures are developed to reduce structural failure severity and increase overall safety of the inhabitants in regular earthquakes. However, typical seismic design of structures cannot provide absolute safety during intense earthquakes and prevent drastic disasters completely (Rezaian, 2014).

In the last two decades, theory of structural reliability against earthquakes has been discussed and developed by many investigators and can be considered as one of the most fundamental designing aspects of recent structures. In the practical viewpoint, reliability analysis has been conducted for many structures all around the world and the effectiveness of the procedure has been verified and reported by different designers and researchers (Jahani, 2012). Advancing of computer programs and decrease of computing time provide suitable infrastructure to apply more uncertainty parameters in seismic design of structures. Consequently, consideration of various uncertainty parameters enhances the quality and effectiveness of seismic design procedure. For a high quality seismic design of structures, it is expected that different seismic risks and structural and loading complexities would be considered. Neglecting of any considerable variable in seismic design may cause severe disaster during the operation of structures within earthquake occurrence and also after the coincidence. Therefore, it is expected that constructing buildings especially in urban areas should be based on consideration of reliability and safety of the structures against earthquakes. One of the most important problems that must be considered is the level of reliability and safety during the lifetime of a system. This issue can be solved using theories and tools for structural reliability assessment. Based on theories of structural reliability, one can use the theory of probability to convert structural parameters with inherent uncertainty to mathematical correlations. Therefore, safety considerations of structural operation can be embedded into seismic design of structures using quantitative data (Hong et al., 2010).

It is noteworthy that evaluation of structural reliability is not just a contemporary concern among 
engineers. There has been many efforts to find the seismic risk of structures since (Datta, 2010; Jahani et al., 2013). In traditional methods, the reliability of structures is determined based on applying safety coefficients in their seismic design (Jahani, 2012). These safety coefficients have been assigned usually with a same weight to the designing correlations to consider different random effective parameters in structures including loading conditions, materials, geometry and boundary conditions. Applying coefficients provides a proportional guarantee for structures for not facing failure or reaching to threshold stresses or allowable deformations. This methodology is based on the preliminary structural guideline and approximate solutions of structural analyses (Bojórquez et al., 2008; Watstein, 1953).

Applying random effective parameters in structures based on reliability theories have been considered since 1970s (Jahani, 2012) has been recognized as one of the most appropriate and robust solutions to predict the functionality of structures with acceptable procession in practical applications (Moosavi, 2012). Using nonlinear time history analysis is seemed to be one of the most appropriate methods for simulation of earthquake effects on structures (Jankowiak and Tlodygowski, 2005). However, this method has also its own disadvantages including being a time consuming and costly method for conventional designs, technical complexities for providing necessary input parameters, lack of sufficient statistical data for providing equivalent records for different circumstances (Sayyar-Roudsari et al., 2019; 2018).

\section{Reliability Analysis}

In the recent century, the theory of reliability analysis has been developed considerably. The first period of the theory development can be considered from 1920 to 1960 . In this period, different investigations developed different aspects of theory of reliability analysis (Freudenthal, 1947; Mayer, 1926; Weibull, 1939). Other investigators developed various concepts of structural random incidences (Basler, 1960; Johnson, 1953; Plum, 1950). However, in practical designing methods, these developments have not been used until 1960s. Conventional designing procedures were based on other investigations in the area of linear elastic methods, plastic methods, structural analysis and mathematical formulation of especial structures such as shell systems. In these investigations, although forces and strength parameters were considered as uncertain parameters, extreme maximum and minimum limits were assumed for their threshold and safety coefficient were applied for considering differences in construction methods. However, even safety coefficients were assumed based on engineering judgment. One of the most important parameters in safety zones of structures were relative distribution of random variables.

Mayer in Germany (1926) and later Basler in Switzerland (1960) provided specific measurement for explaining reliability of structures using Cornell reliability index based on second moment (Cornell, 1969). Forssell (1924) explained optimization criterion for structures as a design which minimize total required cost including costs for initial construction cost and expected costs due to the structural failure.

Based on Mayer investigations, the design of structures would be conducted considering average and standard deviation of random variables. Plum (1950) evaluated the differences between economical safety limits and failure rates in reinforced concrete slabs. Johnson (1953) provided a comprehensive solution based on structural reliability and optimal design theories including statistical theories of developed resistance which had been suggested by Weibull (1939). In another study by Freudenthal (1947), primary reliability of structures under accidental loading conditions were discussed. The results of this study were used by a wide range of engineers. Between "19671974" structural reliability issues were taken into consideration by many investigators including Freudenthal (1947) Ferry-Borges and Castanheta (1971), Pugsley (1966), Johnson (1953) and Turkstra (1970). These investigators provided designing criteria for structures considering different uncertainty parameters and risk factors.

Generally, uncertainty parameters can be categorized in three different aspects including: (1) accidental uncertainties due to variation of excitation, (2) statistical uncertainties due to estimation of different parameters describing a statistical model and (3) uncertainties which are based on mathematical simplification of complicated physical phenomenon. Some examples of mathematical simplifications are linear analysis of nonlinear materials and discrete modeling with limited degree of freedom for a continuous variables. In spite of accidental uncertain variables due to variation of excitation which cannot be reduced, variables based on the last two categories can be modified and decreased. For instance, a comprehensive collection of data or samples can reduce uncertainties due to statistical issues. Similarly, detailed modified mathematical model can reduce uncertain variables of a simplified mathematical solution. Therefore, conducting a more complicated model with a thorough database can decrease uncertainties.

In dynamic reliability analysis of structures, uncertain parameters of earthquake can affect the estimation of reliability solution considerably. Therefore, dynamic uncertainty parameters are taken into more consideration than other uncertainty parameters. In practice, seismic reliability analysis of structures are based on considering 
random ground motions, inherent uncertainty of earthquake happenings and parameters related to earthquake amplitude. It is noteworthy that some investigators combine both seismic random variables and physical and strength of material uncertainties in a specific designing procedure (Fallahi et al., 2018). However, considering both series of uncertainties can make the analysis too complicated and impractical.

Probability models which are widely used for describing the distribution of uncertainty parameters are including uniform, exponential, normal lag and Poisson's distributions. There would be several different dynamic reliability methods based on considering the type of the distribution. Moreover, material properties and other uncertain parameters may affect analytical methods. Using approximate correlations for material properties can reduce the complexity of solutions (Datta, 2010).

\section{Formulation of Reliability Analysis}

Different formulation method can be used for reliability analyses. Two different categories can be mentioned for the formulation methods including constant time and variable time problems. In each of these two categories, a limit state function can be defined based on different criteria including functionality, ultimate stress, etc. The purpose of reliability analysis is to find the probability of limit state failure or violation of limit state conditions. For problems with constant time, $g(x)=0$ defines the limit state function where $\mathrm{x}$ is a collection of random variables including $x_{1}, x_{2}, \ldots, x_{n}$. In this function, $g(x) \leq 0$ shows the failure status. Therefore, the probability of failure is defined as following equation (Datta, 2010):

$$
P_{f}=p[g(x) \leq 0]=\int_{D} f(x) d x
$$

where, $f(x)$ is the density function of jointed probability for $g(x)=0$ and integration of domain of $D$ shows the location of $g(x) \leq 0$.

Figure 1 shows the mentioned concept for two special random variables. The integration of an appropriate probability density function is the hatched zone shows the reliability capability of the structure against failure in a limit state of $g\left(x_{1}, x_{2}\right)=0$. A time dependent reliability problem is in a case that the limit state function would be dependent to time.

In this case the limit state function is defined based on $g(x, y(t))$; where $x$ is a set of random variables and $y(t)$ is a time dependent vector of random process. In these problems the failure status is passing of vector process of $y(t)$ through limit state surface of $g(x, y)=0$ as shown in Fig. 2. Therefore, we have (Datta, 2010):

$$
P_{f}=\int p[\min g(x, y(t)) \leq 0 \mid x] f(x) d x
$$

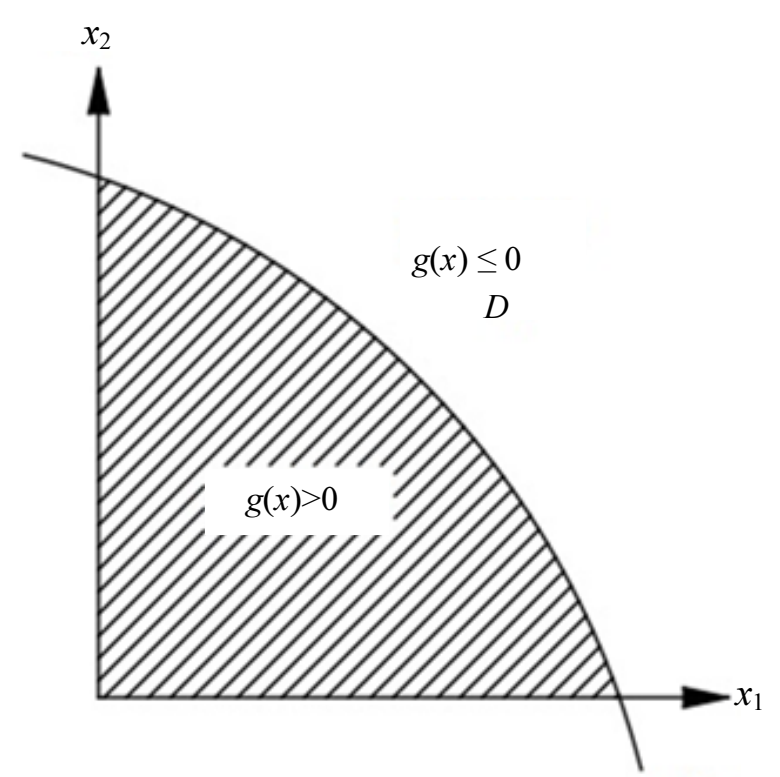

Fig. 1: Reliability capability concept with two random variables (Datta, 2010)

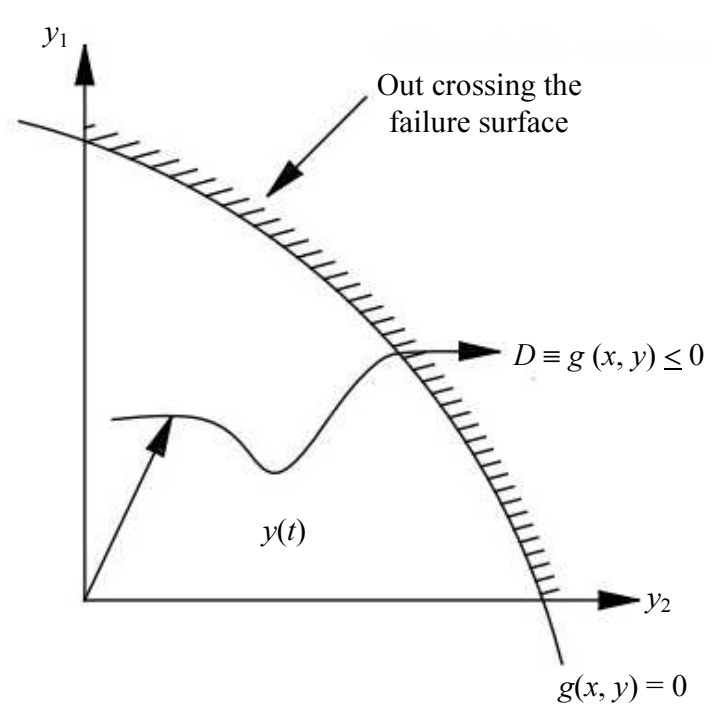

Fig. 2: Reliability capability problem with time variable (Datta, 2010)

where, $T$ is the lifetime of the structure and $f(x)$ is jointed probability density function. In Equation (2), the conditional probability of the phrase in the bracket can be evaluated by a statistical analysis. An accurate solution for Equation (2) would be complicated. This is because of complexity of evaluation of the conditional probability of the phrase in the bracket and also determining the jointed probability of dense function $f(x)$.

The second item is a reason for inability for acquiring an exact solution for integral of Equation (2). Therefore, 
there is a wide range of approximation and assumption for analyzing the reliability capability based on Equation (2). However, in different reliability studies, adequate assumptions have been assumed to evaluate seismic reliability capability of structures (Datta, 2010).

The threshold crossing reliability analysis is the outcrossing analysis in which exceedance probability of a threshold value of the response is determined. The threshold crossing reliability of the structure is defined as one minus the value of the threshold crossing probability. Considering a frame that has uncertain properties represented by the uncertainties of the EI values of beams and columns, the time history of excitation is deterministic. The problem is formulated as a time variant reliability problem with a limit state function defined as:

$$
g(x, t)=u_{0}-u(x, t)
$$

where, $u_{0}$ is the threshold value of the top displacement of a frame and $u(x, t)$ is the top-story displacement of the frame at a given time $(t)$. The $u(x, t)$ is a function of a number of random variables given by the vector $x$. Assuming the random variables to be independent and normally distributed variables and the Taylor series expansion of the limit state function to be truncated at the first-order term, the mean and variance of $g(x, t)$ can be determined.

\section{Model Structures}

In this study, five models of steel moment resisting frame with 3, 5, 7, 10 and 15 floors are selected. It is assumed that connections are rigid in all of the models. Spans of frames are $5 \mathrm{~m}$ and the height of each floor is 3.2 m. According to ASCE/SEI 41-13 (ASCE, 2017), it is assumed that structures are constructed in area with high hazard of earthquake with soil type of III. Figure 3 and 4 and Table 1 show the detail of structures. As shown in Fig. 3 All of frames have three spans. It is assumed that structures are residential buildings with medium level of significance.

The static loading of structures are based on standard guideline of ASCE/SEI 41-13 (ASCE, 2017). The dead and live load for all of stores except the roof level are 2500 and $1000 \mathrm{~kg} / \mathrm{m}$, respectively. The roof dead load for models with 3 and 5 floors are $1750 \mathrm{~kg} / \mathrm{m}$, for models with 7 and 10 floors are $2083 \mathrm{~kg} / \mathrm{m}$ and for 15 floor model is $2250 \mathrm{~kg} / \mathrm{m}$. Live load for all models are assumed as $750 \mathrm{~kg} / \mathrm{m}$. For the study, the degree of significance is assumed as 1 , behavior coefficient is 0 and the Peak Ground Acceleration (PGA) assumed as $0.35 \mathrm{~g}$. Effects of P- $\Delta$ has been considered for designing structures. For structural design, ETABS version 2013 (CSI, 2013) and code of UBC97-ASD (UBC, 1997) have been used. It is noteworthy, that for simplicity, the interaction between soil and structures is neglected.

Yielding stress $\left(f_{y}\right)$ of the steel material used in the analysis is $2400 \mathrm{~kg} / \mathrm{cm}^{2}$. Also, the modulus of elasticity (E) of the steel is considered as $2.1 \times 10^{6} \mathrm{~kg} / \mathrm{cm}^{2}$ and second stiffness coefficient $(\alpha)$ of the steel is assumed as 0.05 (Gerami and Abdollahzadeh, 2015).

In this investigation earthquake records in the study of Gerami and Abdollahzadeh (2015) are used for evaluating the reliability capability of frames. Prosperities of these records are shown in Table (2). The time step for input accelerations are considered as 0.005 seconds. Based on ASCE/SEI 41-13 (ASCE, 2017), 5 percent of critical damping is assumed for seismic analysis of models. In near-field acceleration inputs both the maximum free-field acceleration and directional effects are more intense than far-field acceleration data.

Table 1: Geometry properties of structural sections

\begin{tabular}{|c|c|c|c|c|c|}
\hline Section No. & Section name & $\mathrm{B}(\mathrm{cm})$ & $\mathrm{t}(\mathrm{cm})$ & $\mathrm{H}(\mathrm{cm})$ & $\mathrm{S}(\mathrm{cm})$ \\
\hline B1 & 2PL150*12PL276*8 & 15 & 1.2 & 30 & 0.8 \\
\hline B2 & 2PL150*15PL270*8 & 15 & 1.5 & 30 & 0.8 \\
\hline B3 & 2PL200*15PL270*8 & 20 & 1.5 & 30 & 0.8 \\
\hline B4 & 2PL200*20PL260*8 & 20 & 2.0 & 30 & 0.8 \\
\hline B5 & 2PL200*20PL310*10 & 20 & 2.0 & 35 & 1.0 \\
\hline B6 & 2PL200*20PL360*10 & 20 & 2.0 & 40 & 1.0 \\
\hline B7 & 2 PL250*20PL310*10 & 25 & 2.0 & 35 & 1.0 \\
\hline B8 & 2 PL250*20PL360*10 & 25 & 2.0 & 40 & 1.0 \\
\hline $\mathrm{C} 1$ & BOX $150 * 150 * 10$ & 15 & 1.0 & 15 & 1.0 \\
\hline $\mathrm{C} 2$ & BOX $200 * 200 * 12$ & 20 & 1.2 & 20 & 1.2 \\
\hline $\mathrm{C} 3$ & BOX $200 * 200 * 15$ & 20 & 1.5 & 20 & 1.5 \\
\hline $\mathrm{C} 4$ & BOX $200 * 200 * 20$ & 20 & 2.0 & 20 & 2.0 \\
\hline $\mathrm{C} 5$ & $\mathrm{BOX} 250 * 250 * 20$ & 25 & 2.0 & 25 & 2.0 \\
\hline C6 & $\mathrm{BOX} 250 * 250 * 25$ & 25 & 2.5 & 25 & 2.5 \\
\hline $\mathrm{C} 7$ & $\mathrm{BOX} 300 * 300 * 25$ & 30 & 2.5 & 30 & 2.5 \\
\hline $\mathrm{C} 8$ & $\mathrm{BOX} 300 * 300 * 30$ & 30 & 3.0 & 30 & 3.0 \\
\hline C9 & $\mathrm{BOX} 350 * 350 * 20$ & 35 & 2.0 & 35 & 2.0 \\
\hline $\mathrm{C} 10$ & $\mathrm{BOX} 350 * 350 * 25$ & 35 & 2.5 & 35 & 2.5 \\
\hline C11 & $\mathrm{BOX} 350 * 350 * 30$ & 35 & 3.0 & 35 & 3.0 \\
\hline
\end{tabular}


Majid Mahjoor Lotf Abadi / American Journal of Engineering and Applied Sciences 2019, 12 (2): 204.213 DOI: $10.3844 /$ ajeassp.2019.204.213

Table 2: Earthquake records

\begin{tabular}{|c|c|c|c|c|c|c|c|}
\hline No. & Earthquake & Year & Station & $\mathrm{R}(\mathrm{km})$ & PGA (g) & $\mathrm{T}_{\mathrm{p}}(\mathrm{sec})$ & $\mathrm{T}_{\mathrm{m}}(\mathrm{sec})$ \\
\hline 1 & Chi-Chi, Taiwan & 1999 & CHY065 & 83.43 & 0.1 & 0.56 & 0.79 \\
\hline 2 & Chi-Chi, Taiwan & 1999 & TAP095 & 109.01 & 0.15 & 0.98 & 0.84 \\
\hline 3 & Loma Prieta & 1989 & CDMG58224 & 72.20 & 0.24 & 0.32 & 0.86 \\
\hline 4 & Loma Prieta & 1989 & CDMG58472 & 74.26 & 0.26 & 0.64 & 0.85 \\
\hline 5 & Kobe, Japan & 1995 & HIK & 95.72 & 0.14 & 0.60 & 0.76 \\
\hline 6 & Loma Prieta & 1989 & CDMG58223 & 58.65 & 0.23 & 0.30 & 0.53 \\
\hline 7 & Manjil, Iran & 1990 & Qazvin & 49.97 & 0.13 & 0.16 & 0.46 \\
\hline 8 & Northridge & 1994 & CDMG13122 & 82.32 & 0.10 & 0.38 & 0.44 \\
\hline 9 & Tabas, Iran & 1978 & Ferdows & 91.14 & 0.10 & 0.24 & 0.29 \\
\hline 10 & Kocaeli, Turkey & 1999 & Bursa Tofas & 60.43 & 0.10 & 0.68 & 0.93 \\
\hline 11 & Denali, Alaska & 2002 & Pump St. 10 & 2.74 & 0.32 & 0.94 & 1.52 \\
\hline 12 & Bam, Iran & 2003 & Bam & $\mathrm{R}<15$ & 0.59 & 0.78 & 0.91 \\
\hline 13 & Chi-Chi, Taiwan & 1999 & CHY101 & 9.96 & 0.44 & 0.90 & 0.98 \\
\hline 14 & Chi-Chi, Taiwan & 1999 & TCU068 & 0.32 & 0.56 & 0.42 & 1.51 \\
\hline 15 & Imperial Valley & 1979 & CDMG 5158 & 1.35 & 0.43 & 0.24 & 1.31 \\
\hline 16 & Northridge & 1994 & DWP 75 & 5.19 & 0.49 & 0.22 & 0.72 \\
\hline 17 & Silakhor, Iran & 2006 & Chalan Cho. & $\mathrm{R}<15$ & 0.45 & 1.52 & 1.82 \\
\hline 18 & Kocaeli, Turkey & 1999 & Y arimca & 4.83 & 0.26 & 0.52 & 1.29 \\
\hline 19 & Zanjiran, Iran & 1994 & Meymand & $\mathrm{R}<15$ & 0.42 & 1.36 & 1.73 \\
\hline 20 & Kobe, Japan & 1995 & Takatori & 0.61 & 0.61 & 1.22 & 1.10 \\
\hline
\end{tabular}

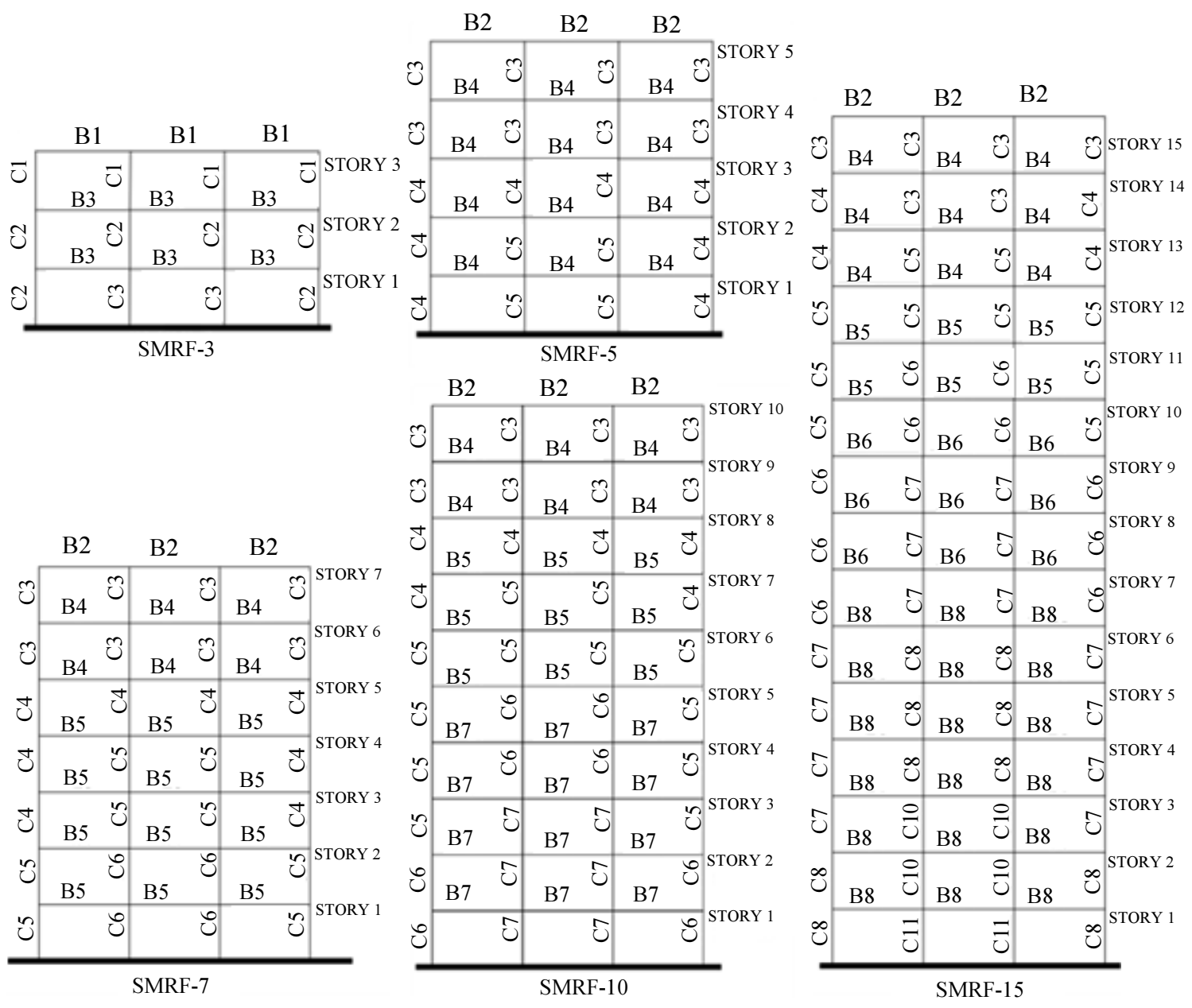

Fig. 3: Structural frames 

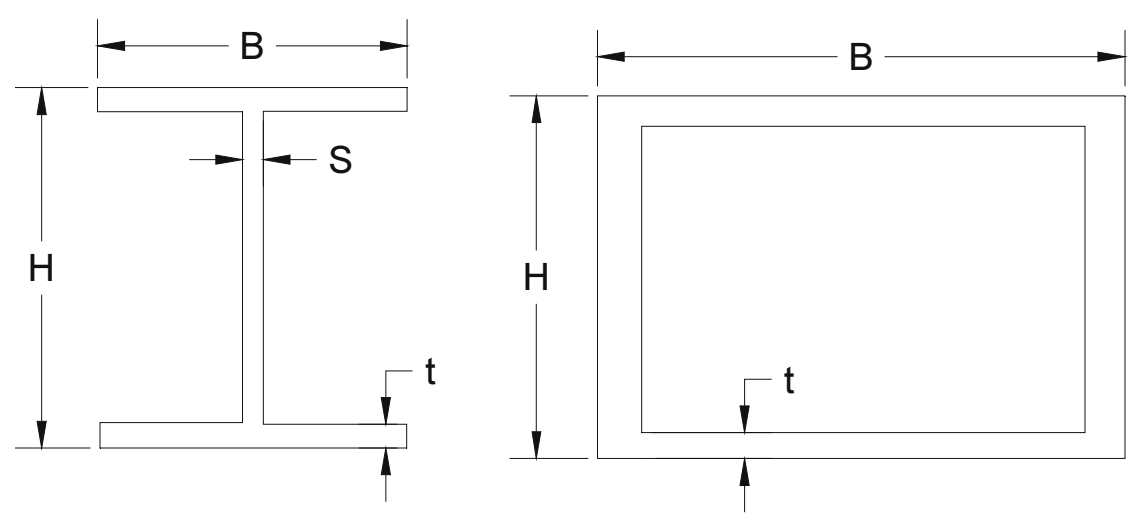

Fig. 4: Cross section of beams and columns (see Table 1 for values)

Table 3: Random variables of steel frames

\begin{tabular}{llll}
\hline Parameter & Distribution & Mean & Covariance \\
\hline $\mathrm{E}$ & Lognormal & $2.1 \times 10^{6}$ & 0.1 \\
$\mathrm{~F}_{\mathrm{y}}$ & Lognormal & 2400 & 0.1 \\
$\alpha$ & Lognormal & 0.05 & 0.1 \\
\hline
\end{tabular}

This issue, increases the response of structures for analysis with near-field input data. For considering directional effects exclusively, all of input accelerations are normalized to have PGA of $0.35 \mathrm{~g}$. It is noteworthy that several methods are available based on seismic standards for earthquake scaling for designing new structures and retrofitting of them. For a specific intensity, the response spectrum of records should be within a specific time period range of standard designing spectrum; or all of the response spectrum of records should be equal with main time period of structures. This method is appropriate for designing of new structures. However, in this study both far-field and near-field records are scaled to a same and constant PGA which is $0.35 \mathrm{~g}$. The reason for this is that the goal of this study is comparing the behavior of models and determining the reliability capability of them and not designing of retrofitting of them. The second reason is that based on ASCE/SEI 41-13 (ASCE, 2017), PGA for both nearfield and far-filed records for an area with constant earthquake hazard is suggested.

\section{Modeling and Reliability Capability Analyses}

For conducting nonlinear dynamic analysis on numerical models and evaluation of reliability capability, OpenSees program (OpenSees, 2006) is used as a finite element software which has been developed by UC Berkeley since 1990. The program is suitable for both micro and macro analyses using different structural elements, material properties and analytical methods. The reliability capability of steel frames has been investigated based on Monte Carlo simulation for time variable conditions considering variation of reliability capability of frames for each input seismic records. Structural uncertainty parameters used for this study is shown in Table 3 . Based on reliability capability analysis using Monte Carlo method, damage likelihood and reliability capability index of frames for different functional levels are calculated. The deformational threshold in different functional levels with unlimited usage capability, the health safety and the failure threshold are determined based on ASCE/SEI 41-13 (ASCE, 2017) according to the following equation:

$\delta_{t}=C_{0} C_{1} C_{2} C_{3} S_{a} \frac{T_{e}^{2}}{4 \pi^{2}} g$

\section{Discussion}

Based on assumed structural variables which are used in the simulation, reliability capability index of each frame for different functional levels are calculated. Table 4 shows the reliability capability index and the damage likelihood of the frame with three floors. The results are determined for 100,000 random samples. The same analytical method is used to evaluate the reliability capability index and the damage likelihood for other frames too.

\section{Results}

Tables 4 to 8 show the reliability capability index and damage probability for all cases of this study. The results are provided for all the earthquake records used in this investigation. 
Majid Mahjoor Lotf Abadi / American Journal of Engineering and Applied Sciences 2019, 12 (2): 204.213 DOI: 10.3844/ajeassp.2019.204.213

Table 4: Reliability capability index and damage probability of the 3-floor frame

\begin{tabular}{|c|c|c|c|c|c|c|}
\hline \multirow[b]{2}{*}{ Earthquake record } & \multicolumn{2}{|c|}{ First operational method } & \multicolumn{2}{|c|}{ Second operational method } & \multicolumn{2}{|c|}{ Third operational method } \\
\hline & $\begin{array}{l}\text { Damage } \\
\text { probability }\end{array}$ & $\begin{array}{l}\text { Reliability } \\
\text { capability }\end{array}$ & $\begin{array}{l}\text { Damage } \\
\text { probability }\end{array}$ & $\begin{array}{l}\text { Reliability } \\
\text { capability }\end{array}$ & $\begin{array}{l}\text { Damage } \\
\text { probability }\end{array}$ & $\begin{array}{l}\text { Reliability } \\
\text { capability }\end{array}$ \\
\hline FF1 & 0.1111 & 1.2205 & 0.0850 & 1.3722 & 0.0669 & 1.4987 \\
\hline FF2 & 0.0499 & 1.6451 & 0.0399 & 1.7513 & 0.0328 & 1.8399 \\
\hline FF3 & 0.0172 & 2.1151 & 0.0086 & 2.3823 & 0.0052 & 2.5584 \\
\hline FF4 & $\approx 0$ & $>8$ & $\approx 0$ & $>8$ & $\approx 0$ & $>8$ \\
\hline FF5 & $\approx 0$ & $>8$ & $\approx 0$ & $>8$ & $\approx 0$ & $>8$ \\
\hline FF6 & 0.0744 & 1.4432 & 0.0592 & 1.6167 & 0.0395 & 1.7560 \\
\hline FF7 & 0.0028 & 2.7685 & 0.0014 & 2.9881 & 0.0002 & 3.5010 \\
\hline FF8 & $\approx 0$ & $>8$ & $\approx 0$ & $>8$ & $\approx 0$ & $>8$ \\
\hline FF9 & $\approx 0$ & $>8$ & $\approx 0$ & $>8$ & $\approx 0$ & $>8$ \\
\hline FF10 & 0.0465 & 1.6791 & 0.0342 & 1.8217 & 0.0254 & 1.9523 \\
\hline NF1 & 0.0224 & 2.0058 & 0.0146 & 2.1797 & 0.0101 & 2.3203 \\
\hline NF2 & 0.0081 & 2.4017 & 0.0036 & 2.6827 & 0.0010 & 3.0726 \\
\hline NF3 & 0.0130 & 2.2250 & 0.0089 & 2.3697 & 0.0060 & 2.5076 \\
\hline NF4 & 0.0056 & 2.5305 & 0.0044 & 2.6170 & 0.0036 & 2.6845 \\
\hline NF5 & 0.0072 & 2.4440 & 0.0042 & 2.6318 & 0.0028 & 2.7633 \\
\hline NF6 & 0.0426 & 1.7205 & 0.0326 & 1.8427 & 0.0241 & 1.9747 \\
\hline NF7 & 0.0135 & 2.2112 & 0.0103 & 2.31424 & 0.0080 & 2.4080 \\
\hline NF8 & 0.0504 & 1.6404 & 0.0390 & 1.7620 & 0.0309 & 1.8664 \\
\hline NF9 & $\approx 0$ & $>8$ & $\approx 0$ & $>8$ & $\approx 0$ & $>8$ \\
\hline NF 10 & 0.1603 & 0.9928 & 0.1279 & 1.1361 & 0.1032 & 1.2633 \\
\hline
\end{tabular}

Table 5: Reliability capability index and damage probability of the 5-floor frame

\begin{tabular}{|c|c|c|c|c|c|c|}
\hline \multirow[t]{2}{*}{ Earthquake record } & \multicolumn{2}{|c|}{ First operational method } & \multicolumn{2}{|c|}{ Second operational method } & \multicolumn{2}{|c|}{ Third operational method } \\
\hline & $\begin{array}{l}\text { Damage } \\
\text { probability }\end{array}$ & $\begin{array}{l}\text { Reliability } \\
\text { capability }\end{array}$ & $\begin{array}{l}\text { Damage } \\
\text { probability }\end{array}$ & $\begin{array}{l}\text { Reliability } \\
\text { capability }\end{array}$ & $\begin{array}{l}\text { Damage } \\
\text { probability }\end{array}$ & $\begin{array}{l}\text { Reliability } \\
\text { capability }\end{array}$ \\
\hline$\overline{\text { FF1 }}$ & 0.0773 & 1.4230 & 0.0620 & 1.5375 & 0.0489 & 1.6555 \\
\hline FF2 & 0.0530 & 1.6161 & 0.0455 & 1.6891 & 0.0390 & 1.7620 \\
\hline FF3 & 0.0129 & 2.2275 & 0.0079 & 2.3295 & 0.0076 & 2.4255 \\
\hline FF4 & $\approx 0$ & $>8$ & $\approx 0$ & $>8$ & $\approx 0$ & $>8$ \\
\hline FF5 & $\approx 0$ & $>8$ & $\approx 0$ & $>8$ & $\approx 0$ & $>8$ \\
\hline FF6 & 0.0189 & 2.0763 & 0.0138 & 2.2021 & 0.0102 & 2.3154 \\
\hline FF7 & $\approx 0$ & $>8$ & $\approx 0$ & $>8$ & $\approx 0$ & $>8$ \\
\hline FF8 & $\approx 0$ & $>8$ & $\approx 0$ & $>8$ & $\approx 0$ & $>8$ \\
\hline FF9 & $\approx 0$ & $>8$ & $\approx 0$ & $>8$ & $\approx 0$ & $>8$ \\
\hline FF10 & 0.0402 & 1.7473 & 0.0329 & 1.8389 & 0.0273 & 1.9209 \\
\hline NF1 & 0.0159 & 2.1454 & 0.0118 & 2.2606 & 0.0094 & 2.3489 \\
\hline NF2 & 0.0001 & 3.6420 & $\approx 0$ & $>8$ & $\approx 0$ & $>8$ \\
\hline NF3 & 0.0112 & 2.2824 & 0.0088 & 2.3736 & 0.0062 & 2.4956 \\
\hline NF4 & 0.0052 & 2.5585 & 0.0036 & 2.6866 & 0.0016 & 2.9303 \\
\hline NF5 & 0.0050 & 2.5690 & 0.0037 & 2.6762 & 0.0022 & 2.8381 \\
\hline NF6 & 0.0298 & 1.8823 & 0.0240 & 1.9768 & 0.0183 & 2.0881 \\
\hline NF7 & 0.0154 & 2.1579 & 0.0120 & 2.2546 & 0.0084 & 2.3878 \\
\hline NF8 & 0.0331 & 1.8363 & 0.0281 & 1.9084 & 0.0239 & 1.9783 \\
\hline NF9 & $\approx 0$ & $>8$ & $\approx 0$ & $>8$ & $\approx 0$ & $>8$ \\
\hline NF10 & 0.0849 & 1.3726 & 0.0702 & 1.4736 & 0.0557 & 1.5919 \\
\hline
\end{tabular}

Table 6: Reliability capability index and damage probability of the 7-floor frame

\begin{tabular}{|c|c|c|c|c|c|c|}
\hline \multirow[b]{2}{*}{ Earthquake record } & \multicolumn{2}{|c|}{ First operational method } & \multicolumn{2}{|c|}{ Second operational method } & \multicolumn{2}{|c|}{ Third operational method } \\
\hline & $\begin{array}{l}\text { Damage } \\
\text { Probability }\end{array}$ & $\begin{array}{l}\text { Reliability } \\
\text { capability }\end{array}$ & $\begin{array}{l}\text { Damage } \\
\text { probability }\end{array}$ & $\begin{array}{l}\text { Reliability } \\
\text { capability }\end{array}$ & $\begin{array}{l}\text { Damage } \\
\text { probability }\end{array}$ & $\begin{array}{l}\text { Reliability } \\
\text { capability }\end{array}$ \\
\hline FF1 & 0.0488 & 1.6558 & 0.0357 & 1.8027 & 0.0238 & 1.9793 \\
\hline FF2 & 0.0378 & 1.7761 & 0.0317 & 1.8556 & 0.0255 & 1.9498 \\
\hline FF3 & 0.0217 & 2.0197 & 0.0165 & 2.1303 & 0.0127 & 2.2349 \\
\hline FF4 & $\approx 0$ & $>8$ & $\approx 0$ & $>8$ & $\approx 0$ & $>8$ \\
\hline FF5 & $\approx 0$ & $>8$ & $\approx 0$ & $>8$ & $\approx 0$ & $>8$ \\
\hline
\end{tabular}




\begin{tabular}{|c|c|c|c|c|c|c|}
\hline FF6 & 0.0411 & 1.7386 & 0.0323 & 1.8475 & 0.0249 & 1.9604 \\
\hline FF7 & 0.000056 & 3.8618 & $\approx 0$ & $>8$ & $\approx 0$ & $>8$ \\
\hline FF8 & $\approx 0$ & $>8$ & $\approx 0$ & $>8$ & $\approx 0$ & $>8$ \\
\hline FF9 & $\approx 0$ & $>8$ & $\approx 0$ & $>8$ & $\approx 0$ & $>8$ \\
\hline FF10 & 0.0255 & 1.9511 & 0.0187 & 2.0793 & 0.0134 & 2.2122 \\
\hline NF1 & 0.1075 & 1.2396 & 0.0691 & 1.4824 & 0.0438 & 1.7071 \\
\hline NF2 & 0.0005 & 3.2848 & 0.0002 & 3.5192 & 0.000058 & 3.8550 \\
\hline NF3 & 0.0259 & 1.9442 & 0.0226 & 2.0023 & 0.0195 & 2.0635 \\
\hline NF4 & 0.0051 & 2.5683 & 0.0031 & 2.7357 & 0.0017 & 2.9275 \\
\hline NF5 & 0.0034 & 2.6982 & 0.0010 & 3.0698 & 0.0000 & 4.3633 \\
\hline NF6 & 0.0231 & 1.9924 & 0.0162 & 2.1397 & 0.0118 & 2.2635 \\
\hline NF7 & 0.0002 & 3.5082 & 0.0000 & 3.8267 & 0.0000 & 4.4192 \\
\hline NF8 & 0.0318 & 1.8546 & 0.0198 & 2.0558 & 0.0120 & 2.2539 \\
\hline NF9 & $\approx 0$ & $>8$ & $\approx 0$ & $>8$ & $\approx 0$ & $>8$ \\
\hline NF10 & 0.0697 & 1.4774 & 0.0575 & 1.5760 & 0.0462 & 1.6824 \\
\hline
\end{tabular}

Table 7: Reliability capability index and damage probability of the 10-floor frame

\begin{tabular}{|c|c|c|c|c|c|c|}
\hline \multirow[b]{2}{*}{ Earthquake record } & \multicolumn{2}{|c|}{ First operational method } & \multicolumn{2}{|c|}{ Second operational method } & \multicolumn{2}{|c|}{ Third operational method } \\
\hline & $\begin{array}{l}\text { Damage } \\
\text { Probability }\end{array}$ & $\begin{array}{l}\text { Reliability } \\
\text { capability }\end{array}$ & $\begin{array}{l}\text { Damage } \\
\text { probability }\end{array}$ & $\begin{array}{l}\text { Reliability } \\
\text { capability }\end{array}$ & $\begin{array}{l}\text { Damage } \\
\text { probability }\end{array}$ & $\begin{array}{l}\text { Reliability } \\
\text { capability }\end{array}$ \\
\hline FF1 & 0.0203 & 2.0459 & 0.0124 & 2.2437 & 0.0065 & 2.4824 \\
\hline FF2 & 0.0231 & 1.9923 & 0.0184 & 2.0868 & 0.0143 & 2.1867 \\
\hline FF3 & 0.0312 & 1.8633 & 0.0259 & 1.9440 & 0.0209 & 2.0336 \\
\hline FF4 & $\approx 0$ & $>8$ & $\approx 0$ & $>8$ & $\approx 0$ & $>8$ \\
\hline FF5 & $\approx 0$ & $>8$ & $\approx 0$ & $>8$ & $\approx 0$ & $>8$ \\
\hline FF6 & 0.0014 & 2.9836 & 0.0006 & 3.2223 & 0.0002 & 3.5252 \\
\hline FF7 & $\approx 0$ & $>8$ & $\approx 0$ & $>8$ & $\approx 0$ & $>8$ \\
\hline FF8 & $\approx 0$ & $>8$ & $\approx 0$ & $>8$ & $\approx 0$ & $>8$ \\
\hline FF9 & $\approx 0$ & $>8$ & $\approx 0$ & $>8$ & $\approx 0$ & $>8$ \\
\hline FF10 & 0.0443 & 1.7020 & 0.0350 & 1.8118 & 0.0267 & 1.9314 \\
\hline NF1 & 0.0276 & 1.9162 & 0.0214 & 2.0250 & 0.0170 & 2.1177 \\
\hline NF2 & 0.0048 & 2.5848 & 0.0029 & 2.7487 & 0.0013 & 2.9955 \\
\hline NF3 & 0.0099 & 2.3293 & 0.0070 & 2.4544 & 0.0042 & 2.6355 \\
\hline NF4 & 0.0071 & 2.4511 & 0.0047 & 2.5961 & 0.0034 & 2.7034 \\
\hline NF5 & 0.0006 & 3.2385 & $\approx 0$ & $>8$ & $\approx 0$ & $>8$ \\
\hline NF6 & 0.0279 & 1.9110 & 0.0196 & 2.0619 & 0.0154 & 2.1594 \\
\hline NF7 & 0.0003 & 3.3774 & 0.0001 & 3.6705 & 0.0000 & 4.0527 \\
\hline NF8 & 0.0142 & 2.1903 & 0.0079 & 2.4092 & 0.0038 & 2.6623 \\
\hline NF9 & $\approx 0$ & $>8$ & $\approx 0$ & $>8$ & $\approx 0$ & $>8$ \\
\hline NF10 & 0.0628 & 1.5311 & 0.0403 & 1.7463 & 0.0199 & 2.0555 \\
\hline
\end{tabular}

Table 8: Reliability capability index and damage probability of the 15 -floor frame

\begin{tabular}{|c|c|c|c|c|c|c|}
\hline \multirow[b]{2}{*}{ Earthquake record } & \multicolumn{2}{|c|}{ First operational method } & \multicolumn{2}{|c|}{ Second operational method } & \multicolumn{2}{|c|}{ Third operational method } \\
\hline & $\begin{array}{l}\text { Damage } \\
\text { Probability }\end{array}$ & $\begin{array}{l}\text { Reliability } \\
\text { capability }\end{array}$ & $\begin{array}{l}\text { Damage } \\
\text { probability }\end{array}$ & $\begin{array}{l}\text { Reliability } \\
\text { capability }\end{array}$ & $\begin{array}{l}\text { Damage } \\
\text { probability }\end{array}$ & $\begin{array}{l}\text { Reliability } \\
\text { capability }\end{array}$ \\
\hline FF1 & 0.0050 & 2.5728 & 0.0023 & 2.8249 & 0.0011 & 3.0521 \\
\hline FF2 & 0.0045 & 2.6067 & 0.0029 & 2.7491 & 0.0016 & 2.9318 \\
\hline FF3 & 0.0565 & 1.5848 & 0.0432 & 1.7136 & 0.0329 & 1.8385 \\
\hline FF4 & $\approx 0$ & $>8$ & $\approx 0$ & $>8$ & $\approx 0$ & $>8$ \\
\hline FF5 & $\approx 0$ & $>8$ & $\approx 0$ & $>8$ & $\approx 0$ & $>8$ \\
\hline FF6 & 0.0008 & 3.1408 & $\approx 0$ & $>8$ & $\approx 0$ & $>8$ \\
\hline FF7 & $\approx 0$ & $>8$ & $\approx 0$ & $>8$ & $\approx 0$ & $>8$ \\
\hline FF8 & $\approx 0$ & $>8$ & $\approx 0$ & $>8$ & $\approx 0$ & $>8$ \\
\hline FF9 & $\approx 0$ & $>8$ & $\approx 0$ & $>8$ & $\approx 0$ & $>8$ \\
\hline FF10 & 0.0355 & 1.8054 & 0.0277 & 1.9153 & 0.0219 & 2.0154 \\
\hline NF1 & 0.0195 & 2.0635 & 0.0147 & 2.1777 & 0.0118 & 2.2621 \\
\hline NF2 & 0.0045 & 2.6055 & 0.0026 & 2.7841 & 0.0006 & 3.2323 \\
\hline NF3 & 0.0001 & 3.5490 & 0.0000 & 4.0172 & 0.0000 & 4.4712 \\
\hline NF4 & 0.0053 & 2.5501 & 0.0038 & 2.6645 & 0.0029 & 2.7524 \\
\hline NF5 & 0.0006 & 3.2379 & 0.0001 & 3.6773 & 0.0000 & 4.1018 \\
\hline NF6 & 0.0096 & 2.3400 & 0.0049 & 2.5817 & 0.0002 & 3.5368 \\
\hline NF7 & 0.0000 & 3.8624 & $\approx 0$ & $>8$ & $\approx 0$ & $>8$ \\
\hline NF8 & 0.0314 & 1.8599 & 0.0177 & 2.1032 & 0.0072 & 2.4457 \\
\hline NF9 & $\approx 0$ & $>8$ & $\approx 0$ & $>8$ & $\approx 0$ & $>8$ \\
\hline NF10 & $\approx 0$ & $>8$ & $\approx 0$ & $>8$ & $\approx 0$ & $>8$ \\
\hline
\end{tabular}




\section{Conclusion}

In this investigation, reliability capability and damage likelihood of steel moment frames against ten different near-field and far-field earthquake input parameters have been conducted. The models were based on five different frames with 3, 5, 7, 10 and 15 floors with the floor height of $3.2 \mathrm{~m}$ and span length of $5 \mathrm{~m}$. According to results, different responses have been recorded for different acceleration input for near-field and far-field zones. As was observed in a specific structure for different accelerograms in the near field and far field different answers obtained. The reliability capability of steel frames for far-field records were more than nearfield ones. Therefore, frames facing near-field seismic loads are experience upper values of the functionality limit in longer time intervals. This means that these frames located in near-field areas with high hazard of earthquake will experience severe damages. Determining the reliability capability using Monte Carlo method demonstrated that the response of structures is highly dependent to the distribution of random variables, their means and standard deviations. Based on the results, it was seen that when the standard deviation of parameters is higher, the convergence of analytical responses decreases.

\section{Acknowledgement}

Author appreciate and grateful to the E. Jahani and H. Hamidi Jamnani for their valuable help during 2013-15.

\section{Ethics}

This article is original and contains unpublished material. Author declare that are not ethical issues and no conflict of interest that may arise after the publication of this manuscript.

\section{References}

ASCE, 2017. Seismic Evaluation and Retrofit of Existing Buildings. 1st Edn., American Society of Civil Engineers, Reston, Virginia. ISBN-10: 0784414858, pp: 550.

Basler, E., 1960. Analysis of structural safety. ASCE Annual Convention, Boston, MA.

Bojórquez, E., A. Terán-Gilmore, S.E. Ruiz and A. Reyes-Salazar, 2008. Evaluation of structural reliability of steel frames considering cumulative damage. The 14th World Conference on Earthquake Engineering, Oct. 12-17, Beijing, China.

Cornell, C.A., 1969. A probability-based structural code. J. Am. Concrete Institute, 66: 974-985.

CSI, 2013. ETABS, Computers and Structures, Inc.
Datta, T.K., 2010. Seismic Analysis of Structures. 1st Edn., John Wiley and Sons Publishing. ISBN-10: 047082462X, pp: 464.

Fallahi, M., S. Sayyar-Roudsari, M. Haghighfar and R. Madandoust, 2018. Modeling of reinforced concrete frames with Infill walls under cyclic loading Strengthening with CFRP. Am. J. Eng. Applied Sci., 11: 1086-1099. DOI: 10.3844/ajeassp.2018.1086.1099

Ferry-Borges, J. and M. Castanheta, 1971. Structural safety. Laboratorio Nacional de Engenharia Civil.

Forssell, C., 1924. Economy and construction. Sunt Fornuft., 4: 74-77.

Freudenthal, A.M., 1947. The Safety of structures. Transactions ASCE, 122: 20-32.

Gerami, M. and D. Abdollahzadeh, 2015. Vulnerability of steel moment-resisting frames under effects of forward directivity. Structural Design Tall Special Build., 24: 97-122. DOI: 10.1002/tal.1156

Hong, H.P., P. Hong and W. Wang, 2010. Reliability of steel frames designed in accordance with the National Building Code of Canada seismic provisions and its implication in codified design. Eng. Structures, 32: 1284-1291.

Jahani, E., 2012. Fuzzy Reliability Theories Using Metaheuristic. PhD. Thesis, Unpublished dissertation in partial fulfillment of the requirements for the degree of Doctor of Philosophy, Iran University of Science and Technology.

Jahani, E., M. Shayanfar and M. Barkhordari, 2013. Structural reliability based on Genetic AlgorithmMonte Carlo (GAMC), Advances Structural Eng.. 16: 419-426. DOI: 10.1260/1369-4332.16.2.419

Jankowiak, T. and O. Tlodygowski, 2005. Identification of parameters of concrete damage plasticity constitutive model. Poznan University of Technology, Institute of Structural Engineering, Ul. Piotrowo 5, 60-975 Poznan, Poland.

Johnson, A.I., 1953. Strength, safety and economical dimensions of structures. Statens Kommitte Byggnadsforskining Meddelanden.

Mayer, M., 1926. Sicherheit der Bauwerke. 1st Edn., Springer Verlag, Berlin.

Moosavi, A.S.M., 2012. Reliability capability analysis of steel frames using form method. PhD. Thesis, Unpublished dissertation in partial fulfillment of the requirements for the degree of Master of Science, Pardisan Higher Education Institute.

OpenSees, 2006. OpenSees. The Regents of the University of California, Berkeley, CA.

Plum, N.M., 1950. Is the design of our houses rational when initial when initial cost, maintenance and repair are taken into account? Ingenioren, 50: 454.

Pugsley, A., 1966. The Safety of Structures. 1st Edn., Edward Arnold, London. 
Rezaian, S., 2014. Evaluation of incremental nonlinear dynamic analysis method for estimating restrained braced frames. PhD. Thesis, Unpublished dissertation in partial fulfillment of the requirements for the degree of Master of Science, ARYAN Institute of Science and Technology, Iran.

Sayyar-Roudsari, S., S.A. Hamoush and S.M. Soleimani, 2019. Evaluation of large-size reinforced concrete columns strengthened for axial load using fiber reinforced polymers. Eng. Structures J., 178: 680-693. DOI: 10.1016/j.engstruct.2018.09.071

Sayyar-Roudsari, S., S.A. Hamoush, S.M. Soleimani, T.A. Lebdeh and M. Haghighfar, 2018. Analytical study of reinforced concrete beams strengthened by FRP bars subjected to impact loading condition. Am. J. Eng. Applied Sci.
Turkstra, C.J., 1970. Theory of structural design decisions. Solid Mechanics Division, University of Waterloo.

UBC, 1997. Uniform building code allowable stress design: International code council, Inc.

Watstein, D., 1953. Effect of straining rate on the compressive strength and elastic properties of concrete. Proceedings of the International Concrete Abstracts Portal, (CAP' 53), American Concrete Institute, 450-451: 729-744. DOI: 10.4028/www.scientific.net/AMR.450-451.244

Weibull, W., 1939. A Statistical theory of the strength of materials. Royal Swedish Institute of Engineering Research, Stockholm, Sweden. 